\title{
Zur Rechtsentwicklung in Nordkorea
}

\author{
Von Arno Wohlgemuth
}

Nordkorea gehört heute noch zu denjenigen Staaten, über deren geltendes Rechtssystem nur verstreute und lückenhafte Informationen hierzulande erhältlich sind.1 Radio- und Pressemeldungen von nordkoreanischer Seite, so spärlich sie auch sein mögen, dürfen deshalb nicht übergangen werden, will man nicht gänzlich diesen Teil der Rechtsfamilien in der Welt aus dem Blick verlieren.

\section{Verfassungsrecht}

Auf ihrer 3. Sitzung der 9. Legislaturperiode vom 8. bis 10. April 1992 verabschiedete die Oberste Volksversammlung der Demokratischen Volksrepublik Korea (DVRK) eine Novelle zur Verfassung vom 27. Dezember 1972. Úber den Inhalt der Verfassungsrevision ist hier bisher nur soviel bekannt, daß die Änderungen und Ergänzungen die Ideologie und Theorie widerspiegeln, wie sie jüngst von Kim Il-sung und der Partei vorgetragen wurden. Es wird vermutet, daß Art. 93 der Verfassung, wonach der Präsident der DVRK gleichzeitig Oberbefehlshaber der Volksstreitkräfte ist, den letzten politischen Veränderungen angepaßt wurde. Im Dezember 1991 nämlich wurde der älteste Sohn und designierte Nachfolger des Präsidenten Kim Il-sung, Kim Jong-il, zum Oberbefehlshaber der Volksstreitkräfte emannt.2

\section{Handels-, Zivil- und Familienrecht}

Auf derselben Sitzung beschloß die Oberste Volksversammlung der DVRK ein neues Handelsgesetz. Ủber dessen Einzelheiten wurde nichts berichtet, ${ }^{3}$ ebensowenig wie über die je-

1 Siehe z.B. Arno Wohlgemuth, Von Juche zu Joint Venture: Das Recht der nordkoreanisch-ausländischen Gemeinschaftsuntemehmen, in: WGO - Monatshefte für Osteuropäisches Recht 30 (1988), 265-284; ders., Democratic People's Republic of Korea (Stand: Juli 1989), in: Intemational Encyclopedia of Comparative Law, Vol. I, National Reports, Supplement (im Druck befindlich).

2 The SPA Makes a Partial Revision of Constitution, Vantage Point - Development in North Korea, Vol. XV, No. 4 (April 1992), 25; Summary of World Broadcasts, Part 3, Far East, BBC Monitoring, Reading/Berkshire, U.K. v. 17.4.1992, Nr. 1358/C3/1 (= SWB FE/1358/C3/1 v. 17.4.1992).

3 The SPA Makes a Partial Revision, a.a.O. 
nigen des von der Obersten Volksversammlung der DVRK auf ihrer 2. Sitzung der 9. Legislaturperiode am 12. April 1991 angenommenen Familiengesetzes. 4

Dagegen wurde von südkoreanischer Seite ausführlich über das neue Zivilgesetzbuch vom 12. April 1991 berichtet. Das nordkoreanische ZGB ist die erste Kodifikation ihrer Art seit Bestehen Nordkoreas. 5 Das ZGB gliedert sich in vier Teile und 13 Kapitel mit 271 Artikeln. Die vier Teile behandeln (I) allgemeine Grundsätze, (II) die Eigentumsordnung, (III) das Schuldrecht und (IV) die zivilrechtliche Haftung und Verjährung. Die Allgemeinen Grundsätze sind untergliedert in drei Kapitel, (1) Zweck und Ziel des Zivilgesetzbuches, (2) die Grundsätze des Zivilrechts und (3) die Gültigkeit von Zivilrechtsakten. Der 2. Teil über die Eigentumsordnung, der aus vier Kapiteln besteht, enthält (1) allgemeine Grundsätze der Eigentumsordnung, (2) das Staatseigentum, (3) das Gemeinschafts- und Kollektiveigentum und (4) das persönliche Eigentum. Der 3. Teil über das Schuldrecht, ebenfalls in vier Kapitel unterteilt, regelt (1) allgemeine Grundsätze, (2) Planverträge oder Wirtschaftsverträge, (3) allgemeine Verträge und (4) die ungerechtfertigte Bereicherung. Die beiden letzten Kapitel des letzten Teils treffen Bestimmungen über (1) die zivilrechtliche Haftung und (2) die Verjährung.

\section{Straf- und Strafprozeßrecht}

Auf ihrer Sitzung im April 1992 erließ die Oberste Volksversammlung der DVRK ebenfalls ein neues Strafprozeßgesetz,6, welches dasjenige vom 3. März 1950 in der Fassung vom 18. Juni 19547 ablöst. Auch hierzu ist Näheres nicht bekannt.

Etwas anders verhält es sich mit dem Strafgesetzbuch vom 5. Februar 1987, das durch Beschluß Nr. 2 des Ständigen Ausschusses der Obersten Volksversammlung der DVRK in Kraft gesetzt wurde. Es trat an die Stelle des Strafgesetzbuches vom 3. März 19508 in seiner Fassung vom Jahre 1974.

Das neue StGB gliedert sich in sieben Kapitel, 13 Teile und 116 Artikel. Die Kapitel tragen die Überschriften (I) Grundsätze des Strafgesetzbuches, (II) Allgemeine Bestimmungen über Straftaten und Strafen, (III) Straftaten gegen den Staat, (IV) Straftaten gegen das

4 SWB FE/1045i v. 13.4.1991.

5 Chung Jae-kil, North Korea's New Civil Code, Vantage Point - Developments in North Korea, Vol. XV, No. 6 (June 1992), 1-11.

6 The SPA Makes a Partial Revision, a.a.O.

7 Auf Englisch abgedruckt bei Koo-Chin Kang, North Korean Criminal Procedure Code, The Seoul Law Joumal, Vol. XI, No. 2, 151-201.

8 Auf Englisch abgedruckt bei Koo-Chin Kang, Law in Communist Korea: An Analysis of SovietChinese Influence Thereupon, Diss. Cambridge, Mass., Harvard Law School 1969. 
sozialistische Wirtschaftssystem, (V) Straftaten gegen die sozialistische Kultur, (VI) Straftaten gegen die Ordnung des sozialistischen Gemeinschaftslebens und (VII) Straftaten gegen das Leben und Eigentum der Bürger.

Als Hauptstrafen kennt das nordkoreanische StGB die Todesstrafe und Besserungsmaßnahmen durch Arbeit, als Nebenstrafen Verlust des Wahlrechts und Einziehung des Vermögens einer Person. Die Todesstrafe darf nicht verhängt werden gegenüber Minderjährigen, die zur Tatzeit das 17. Lebensjahr nicht vollendet hatten, und gegenüber schwangeren Frauen. Besserungsmaßnahmen durch Arbeit sind ihrem Inhalt nach strafrechtliche Dienstleistungsverpflichtungen für einen Zeitraum zwischen 6 Monaten und 15 Jahren. Lebenslängliche Besserungsmaßnahmen sind ausgeschlossen. Der bloße Freiheitsentzug in Gefängnissen, Umerziehungs- oder Konzentrationslagern als Strafe ist dem StGB unbekannt. Gesamtstrafen dürfen 15 Jahre Arbeitsverpflichtung nicht übersteigen. Nach Verbüßung der Strafe wird der Straftäter ohne jede Bedingung auf freien Fuß gesetzt, er gilt nunmehr als von seiner Straftat entlastet und als unbescholtener Bürger. Eine Sühne wegen früherer Verurteilungen wird nicht gefordert.

Strafgesetze haben keine rückwirkende Kraft, wenn vor Verurteilung durch ein Strafgericht neue Straftatbestände oder höhere Strafen eingeführt werden. Dagegen kommen dem Täter Bestimmungen zugute, welche Handlungen, die zur Tatzeit strafbar waren, vor Verurteilung für straffrei erklären oder mit einer geringeren Strafe belegen.

Kapitel III über Straftaten gegen den Staat enthält in Art. 44-55 Bestimmungen über Verschwörung zum Umsturz der Staatsmacht, den Terrorismus, antistaatliche Propaganda und Hetze, Landesverrat, Spionage, Anstiftung zur bewaf fneten Intervention und zum Abbruch auswärtiger Beziehungen, antistaatliche umstürzlerische Akte und Sabotage sowie feindselige Handlungen gegen Ausländer innerhalb Nordkoreas, Volksverrat und Verheimlichung von Straftaten gegen den Staat. Als Sanktionen kommen alle Haupt- und Nebenstrafen in Betracht.

Art. 46 StGB regelt das Delikt der antistaatlichen Propaganda und Hetze; erfaßt werden Aufwiegelung zum Umsturz, Aufruhr oder zur Untergrabung der Republik und zu anderen antistaatlichen Verbrechen.

Nicht bestraft werden das bloße Studium von Ideologien, Theorien, Systemen oder politischen Programmen, zustimmende oder ablehnende Meinungsäußerungen oder Sympathiebekundungen, wenn nicht zugleich zu staatsfeindlichen Handlungen aufgerufen wird.

Landesverrat liegt nach Art. 47 StGB dann vor, wenn ein Bürger die Republik verläßt und zu einem ausländischen Staat oder dem Feind überläuft und sich als Spion betätigt oder dem Feind Hilfe leistet und dadurch das Land und das Volk verrät. 
"Feindliche Seite" oder "Feind" bedeutet dabei die gegnerische Streitpartei in einem Krieg oder die gegnerischen Guerilleros. Im Falle eines Krieges innerhalb Koreas wäre Südkorea der Feind im Sinne der Bestimmung. In Friedenszeiten ist das jedoch nicht der Fall.

Setzt sich ein Nordkoreaner während Friedenszeiten in einen ausländischen Staat oder nach Südkorea ab, nachdem seine Straftaten, wie Sammlung geheimer Informationen, terroristische Akte oder Gründung einer Geheimorganisation aufgedeckt worden sind, so liegt eine Flucht in feindseliger Absicht vor und nicht nur ein schlichter illegaler Grenzübertritt oder ein rechtswidriges Uberschreiten der Demarkationslinie zu Südkorea. Deswegen wird die Flucht nach Südkorea nach Begehung staatsfeindlicher Akte auch in Friedenszeiten als Landesverrat bestraft.

Die Teilnahme an sportlichen Veranstaltungen von südkoreanischen Institutionen, politischen Parteien oder gesellschaftlichen Organisationen ohne die erforderliche Genehmigung durch nordkoreanische Behörden zählt allein nicht als Landesverrat, ebensowenig die Flucht außer Landes aus Gründen vorübergehender Unzufriedenheit.

Nach Art. 52 StGB gelten als Volksverrat alle Akte, durch welche die nationale Befreiungsbewegung des nordkoreanischen Volkes und dessen revolutionärer Kampf für die Wiedervereinigung und Unabhängigkeit des Landes im Verein mit den das Land beherrschenden Imperialisten unterdrückt und verfolgt werden, oder der Verrat der Interessen der koreanischen Nation an die Imperialisten durch ein Mitglied der koreanischen Nation.

Art. 5 StGB indessen sieht vor, daß Personen, welche Landes- oder Volksverrat begangen haben, straffrei ausgehen, wenn sie sich nach Kräften für die Wiedervereinigung oder die Unabhängigkeit des Landes einsetzen. Das gilt jedoch nicht für Bestrebungen nach Wiedervereinigung durch Umsturz des kommunistischen Systems oder durch dessen Absorption, wohl aber für eine unabhängige und friedliche Wiedervereinigung der beiden Korea in einem einzigen Staat, aber mit verschiedenen Systemen in Nord und Süd.9

9 Criminal Codes's Provisions on Treason and Absconding Explained, SWB FE/1380/B/11-13 v. 14.5.1992. 